\title{
Adenoid cystic carcinoma of the skull base: results with an aggressive multidisciplinary approach
}

\author{
Rohan Ramakrishna, MD, ${ }^{1}$ Shaan M. Raza, MD, ${ }^{1}$ Michael Kupferman, MD, ${ }^{2}$ Ehab Hanna, MD, ${ }^{2}$ and \\ Franco DeMonte, MD ${ }^{1}$
}

Departments of ${ }^{1}$ Neurological Surgery and ${ }^{2} \mathrm{Head}$ and Neck Surgery, MD Anderson Cancer Center, Houston, Texas

\begin{abstract}
OBJECTIVE Adenoid cystic carcinoma (ACC) is a locally aggressive tumor of salivary gland origin. Little data exist to guide treatment when this tumor extends to involve the structures of the skull base.

METHODS Fifty-one patients with a diagnosis of ACC affecting the skull base were identified from a prospective database at MD Anderson Cancer Center (from 1992 to 2010).

RESULTS Median follow-up for study patients was 6.75 years. The 5 - and 10 -year overall survival (OS) rates were $78 \%$ and $50 \%$, respectively. Sixty-six percent of patients had progression of their disease. The 5- and 10-year progressionfree survival (PFS) rates were $46.7 \%$ and $21.0 \%$, respectively. Gross-total resection was achieved in $75 \%$ of patients, with $49 \%$ having microscopically negative margins at the time of first operation. On univariate analysis, resections with microscopically negative margins were associated with a significant OS advantage $(20.1 \pm 3.3$ years $)$ compared with resections that left residual disease, even if microscopic $(10.3 \pm 1.6$ years, $p=0.035)$. In patients who underwent reoperation, the effect persisted, with improved $O S$ in those with negative margins ( $21.4 \pm 0.0$ vs $16.7 \pm 4.0$ years, $p=0.06$ ). The use of adjuvant radiotherapy was associated with an OS advantage ( $16.2 \pm 2.5$ vs $5.5 \pm 2.2$ years, $p=0.03)$ at initial diagnosis and improved PFS ( $7.8 \pm 1.0$ vs $2.1 \pm 0.62$ years, $p=0.005)$, whereas repeat irradiation provided no benefit. The use of adjuvant chemotherapy at diagnosis or at recurrence was not associated with any significant advantage. Multivariate analysis revealed margin-negative resection at initial operation and at recurrence retained OS significance, even after controlling for age, radiation therapy, and T stage.
\end{abstract}

CONCLUSIONS ACC of the skull base is best treated with a multidisciplinary approach aimed at maximal, safe resection. Adjuvant radiotherapy should be offered, whereas chemotherapy does not confer benefit.

http://thejns.org/doi/abs/10.3171/2015.1.JNS142462

KEY WORDS adenoid cystic carcinoma; radiation; skull base; bifrontal craniotomy; lateral rhinotomy; endonasal endoscopy; neuro-oncology; oncology

$\Lambda$ DENOID cystic carcinoma (ACC) is a locally aggressive salivary gland malignancy prone to perineural invasion and metastasis. Local recurrences often involve the skull base, whereas distant metastases most frequently involve the lung, bones, and liver., ${ }^{3,4,27,43,45}$ Standard therapy for this malignancy has most commonly included a strategy of local resection followed by adjuvant radiation therapy. ${ }^{6}, 13,16,17,23,24,28,30,35,38,39,43,46,47,52$ Chemotherapy using agents such as carboplatinum and paclitaxel has been used, but with limited results. 2,11,12,15,26,27,36,41,44,48-50

ACC can arise in any salivary gland, both major and minor. Consequently, these tumors can be located in the tongue, trachea, palate, larynx, and paranasal sinuses. ${ }^{27}$ Tumors in the sinonasal cavity can remain undetected for long periods of time with minimal symptoms. Only after sufficient soft-tissue involvement, bone destruction, or cranial nerve involvement does the malignancy become manifest. Therefore, a strategy of maximal resection with minimal morbidity often presents a substantial therapeutic challenge given the complex anatomy of lesions that involve the paranasal sinuses and extend intracranially into the anterior or middle fossa.

ABBREVIATIONS ACC = adenoid cystic carcinoma; EGFR = epidermal growth factor receptor; ICA = internal carotid artery; OS = overall survival; PFS = progression-free survival; VEGF = vascular endothelial growth factor.

SUBMITTED October 28, 2014. ACCEPTED January 5, 2015.

INCLUDE WHEN CITING Published online August 7, 2015; DOI: 10.3171/2015.1.JNS142462.

DISCLOSURE The authors report no conflict of interest concerning the materials or methods used in this study or the findings specified in this paper. 
In this study, we report the largest experience to date of patients with ACC involving the skull base wherein an aggressive, multidisciplinary approach was undertaken.

\section{Methods}

From 1992 to 2010, 51 consecutive patients (27 males, 24 females) with a pathologically confirmed diagnosis of ACC involving the skull base were identified from a prospectively maintained database at the MD Anderson Cancer Center (Table 1). Patients were seen in a multidisciplinary setting involving neurological surgery, head and neck surgery, plastic surgery, ophthalmology, medical oncology, and radiation oncology. Thirty-two percent of patients had at least 2 operative interventions for their tumor, and $65 \%$ had their first operation and received the entirety of their care at MD Anderson Cancer Center. The remaining patients had their first operation elsewhere and underwent their second operation and the remainder of their care at MD Anderson Cancer Center.

\section{Data Analysis}

Data analysis was performed via standard statistical software (SPSS, IBM Inc.) using the Kaplan and Cox regression methods. ${ }^{10,32}$ Multivariate analysis was performed, but was limited given the sample size.

TABLE 1. Characteristics of 51 patients with ACC*

\begin{tabular}{lc}
\hline \multicolumn{1}{c}{ Characteristic } & Value \\
\hline Sex & \\
$\quad$ Male & $27(53 \%)$ \\
$\quad$ Female & $24(47 \%)$ \\
\hline Age at diagnosis, yrs ${ }^{*}$ & $48.1 \pm 1.83$ \\
\hline Average follow-up, yrs & $8.2 \pm 0.91$ \\
\hline Progression of disease & $66.7 \%$ \\
\hline Average time to progression, yrs ${ }^{*}$ & $4.4 \pm 0.53$ \\
\hline Adjuvant chemotherapy at diagnosis & $13.7 \%$ \\
\hline Adjuvant radiotherapy at diagnosis & $88.3 \%$ \\
\hline Adjuvant chemotherapy at recurrence & $30.1 \%$ \\
\hline Adjuvant radiotherapy at recurrence & $62.5 \%$ \\
\hline Complete resection (>90\%) at initial op & $75.0 \%$ \\
\hline Negative margins at initial op & $48.9 \%$ \\
\hline Complete resection at recurrence & $70 \%$ \\
\hline Negative margins at recurrence & $47.3 \%$ \\
\hline Persistent complication rate at initial op & $2.7 \%$ \\
\hline Pts who underwent $\geq 2$ resections & $32 \%$ \\
\hline Pts requiring free myocutaneous flap & $39.2 \%$ \\
\hline Pts with metastatic disease & $43.0 \%$ \\
\hline Average time to develop metastatic disease, yrs & $4.4 \pm 0.67$ \\
\hline Cavernous sinus involvement & $46 \%$ \\
\hline Perineural invasion & $47.0 \%$ \\
\hline T stage at diagnosis & $20 \%$ \\
\hline T2 & $80 \%$ \\
\hline T4b &
\end{tabular}

Pts = patients.

* Data are presented as \pm SEM.

\section{Radiation}

Adjuvant radiotherapy was given to the vast majority of patients following the initial operation (88\%). In those cases, external beam radiotherapy with a dose of $6000 \mathrm{cGy}$ was most commonly used, with boosts (6600 cGy) given to at-risk areas. ${ }^{8,22,39}$ Gamma Knife stereotactic radiosurgery $(\mathrm{n}=11)$ was most commonly used for small residual disease or for limited new disease (22\%).

\section{Operative Considerations}

The primary goal of surgery was to achieve a marginnegative total resection of the tumor without subjecting the patient to unreasonable potential morbidity (i.e., carotid injury, need for bypass, stroke, orocutaneous fistulas, and malocclusions). In patients with subdural invasion, piecemeal resection was unavoidable but has been previously shown not to negatively influence outcomes in skull-base malignancies. ${ }^{17}$ More recently, where appropriate, patients have also been offered endoscopic approaches, with similar oncological results. ${ }^{28}$ This strategy has been applied to the 3 most common tumoral locations as follows.

\section{Primary Orbit (Lacrimal Gland)}

In these patients, tumors involved the orbital contents and bone, with or without involvement of the superior orbital fissure. Treatment consisted of frontotemporal craniotomy with orbitectomy. Where possible, the superior orbital fissure is transected at a point with negative margins. ${ }^{16}$ An extradural, extracavernous dissection allows for the transection of the superior orbital fissure just anterior to the anterior loop of the cavernous internal carotid artery (ICA).

\section{Primary Anterior Cranial Base/Sinonasal Cavity}

In these patients, tumors involved the sinonasal cavity and extended into the anterior cranial base. Surgical approaches have included the benchmark bifrontal craniotomy/transfacial approach; purely transcranial, transfacial, or endoscopic approaches; and transcranial approaches combined with endoscopic resection of the sinonasal component of the tumor.

\section{Primary Maxillary/Infratemporal/Pterygopalatine Fossa Tumors}

In these patients, the epicenter of the tumor typically originates in the maxilla/palate and involves extensive soft-tissue and bone disruption with tumor extending intracranially via perineural extension through the maxillary, mandibular, or vidian nerves. Additionally, tumors might extend intracranially via orbital involvement with compromise of the superior orbital fissure, or through the infratemporal fossa with extension into the middle cranial base. Approaches consisted of open maxillectomy with or without craniotomy, depending on the tumor extent. If the soft-tissue and bony disease of the skull base could be safely resected without a craniotomy, a single transfacial approach was preferred. This was extended intracranially to resect perineural extensions of tumor along the superior orbital fissure (in combination with orbitectomy), maxillary nerve, mandibular nerve, or vidian nerve by removing the anteromedial wall of the middle cranial fossa. ${ }^{13}$ 
Limited anterolateral cavernous sinus involvement was resected, but cavernous sinus resection or ICA sacrifice was not performed. There were no planned or unplanned carotid bypass procedures.

\section{Results}

Patient characteristics and operative outcomes are displayed in Tables 1 and 2. The mean follow-up for study patients was 8.2 years (median 6.75 years). The average overall survival (OS) and progression-free survival (PFS) were 15.6 years $(95 \%$ CI $10.8-20.3)$ and 7.3 years $(95 \%$ CI 5.6-8.9). The 5- and 10-year overall survival (OS) rates were $78 \%$ (95\% CI 72-84) and 50\% (95\% CI 40-60), respectively. Sixty-six percent of patients had progression of their disease, with mean time to progression of $4.4 \pm$ 0.53 years. The 5- and 10 -year PFS rates were $46.7 \%$ and $21.0 \%$, respectively. Gross-total resection was achieved in $75 \%$ of patients, with $49 \%$ having microscopically negative margins at time of first operation. The 2- and 5-year local control rates were $86 \%$ and $82 \%$ (of those who survived 5 years), respectively.

On univariate analysis, resections with negative margins were associated with a significant OS advantage $(20.1 \pm 3.3$ years) compared with resections that left residual disease, even if microscopic $(10.3 \pm 1.6$ years, $\mathrm{p}=$ 0.035 ) (Fig. 1). In patients who underwent reoperation, the effect persisted, with improved OS in those with negative margins $(21.4 \pm 0.0$ vs $16.7 \pm 4.0$ years, $\mathrm{p}=0.06)$. The use of adjuvant radiotherapy was associated with an OS advantage $(16.2 \pm 2.5$ vs $5.5 \pm 2.2$ years, $p=0.03)$ at initial diagnosis and improved PFS $(7.8 \pm 1.0$ vs $2.1 \pm 0.62$ years, $p=0.005$ ), but had no impact when used at time of recurrence. Of those patients who underwent stereotactic radiosurgery, $73 \%$ demonstrated local control for treated areas. The use of adjuvant chemotherapy at diagnosis or at recurrence was not associated with any significant advantage. The presence of perineural invasion imparted a significant OS disadvantage of nearly $50 \%$. There was no perioperative mortality. The temporary complication rate (within 60 days) was $14.8 \%$ and included temporary postoperative respiratory failure $(n=2)$, neck hematoma requiring evacuation $(n=1)$, epidural hematoma $(n=2)$, CSF leak requiring lumbar drain treatment $(n=2)$, and infection $(n=6)$. The persistent complication rate was $2.7 \%$ and included enopthalmos $(\mathrm{n}=1)$ and malocclusion of mandible $(n=1)$. Forty-three percent of patients developed metastatic disease. Of those patients, $60 \%$ died an average of 2.2 years after the appearance of metastasis, while the remainder survived with stable disease with an average follow-up of $7.7 \pm 1.54$ years. The average number of operative interventions performed at the primary site of disease was $1.41 \pm 0.12$.

In multivariate analysis, margin-negative resection at initial operation and at recurrence retained OS significance, even after controlling for age, radiation therapy, and $\mathrm{T}$ stage.

\section{Discussion}

Adenoid cystic carcinoma is an aggressive salivary gland tumor known for local and lymphovascular inva-
TABLE 2. Factors influencing OS in 51 patients with ACC*

\begin{tabular}{|c|c|c|}
\hline Variable & OS Values (yrs) & p Value \\
\hline Margins at initial op & & 0.035 \\
\hline Negative & $20.1 \pm 3.3$ & \\
\hline Positive & $10.3 \pm 1.6$ & \\
\hline $\mathrm{HR}$ & 2.8 & \\
\hline $95 \% \mathrm{Cl}$ & $1.03-8.0$ & \\
\hline Margins at 2nd op & & $0.06 \dagger$ \\
\hline Negative & $21.4 \pm 0.0$ & \\
\hline Positive & $16.7 \pm 4.0$ & \\
\hline $\mathrm{HR}$ & 6.7 & \\
\hline $95 \% \mathrm{Cl}$ & $0.9-50$ & \\
\hline Adjuvant radiation after 1 st op & & 0.03 \\
\hline Yes & $16.2 \pm 2.5$ & \\
\hline No & $5.5 \pm 2.2$ & \\
\hline $\mathrm{HR}$ & 3.4 & \\
\hline $95 \% \mathrm{Cl}$ & $1.1-10.5$ & \\
\hline Adjuvant radiation after $2 \mathrm{nd}$ op & & 0.76 \\
\hline Yes & $16.2 \pm 4.1$ & \\
\hline No & $13.1 \pm 1.9$ & \\
\hline $\mathrm{HR}$ & 1.2 & \\
\hline $95 \% \mathrm{Cl}$ & $0.43-43.2$ & \\
\hline Adjuvant chemo at 1 st op & & 0.14 \\
\hline Yes & $7.3 \pm 2.1$ & \\
\hline No & $16.3 \pm 2.6$ & \\
\hline$H R$ & 0.44 & \\
\hline $95 \% \mathrm{Cl}$ & $0.14-1.3$ & \\
\hline Adjuvant chemo at 2nd op & & 0.18 \\
\hline Yes & $7.1 \pm 1.8$ & \\
\hline No & $16.1 \pm 2.7$ & \\
\hline $\mathrm{HR}$ & 0.47 & \\
\hline $95 \% \mathrm{Cl}$ & $0.16-1.43$ & \\
\hline Up-front radiation therapy w/o op & & $0.07 \dagger$ \\
\hline Yes & $6.6 \pm 1.5$ & \\
\hline No & $16.6 \pm 2.6$ & \\
\hline $\mathrm{HR}$ & 2.9 & \\
\hline $95 \% \mathrm{Cl}$ & $0.84-10.2$ & \\
\hline Presence of metastatic disease & & 0.05 \\
\hline Yes & $10.3 \pm 2.0$ & \\
\hline No & $20.7 \pm 3.9$ & \\
\hline HR & 0.42 & \\
\hline $95 \% \mathrm{Cl}$ & $0.17-1.0$ & \\
\hline Cavernous sinus invasion & & 0.16 \\
\hline Yes & $11.44 \pm 20.2$ & \\
\hline No & $20.2 \pm 3.9$ & \\
\hline $\mathrm{HR}$ & 0.53 & \\
\hline $95 \% \mathrm{Cl}$ & $0.22-1.3$ & \\
\hline Perineural invasion & & 0.01 \\
\hline Yes & $9.2 \pm 1.5$ & \\
\hline No & $20.7 \pm 3.3$ & \\
\hline$H R$ & 0.27 & \\
\hline $95 \% \mathrm{Cl}$ & $0.09-0.75$ & \\
\hline
\end{tabular}

Chemo = chemotherapy; $\mathrm{NS}=$ not significant.

* Data are presented as \pm SEM.

$\dagger$ NS but strong trend. 


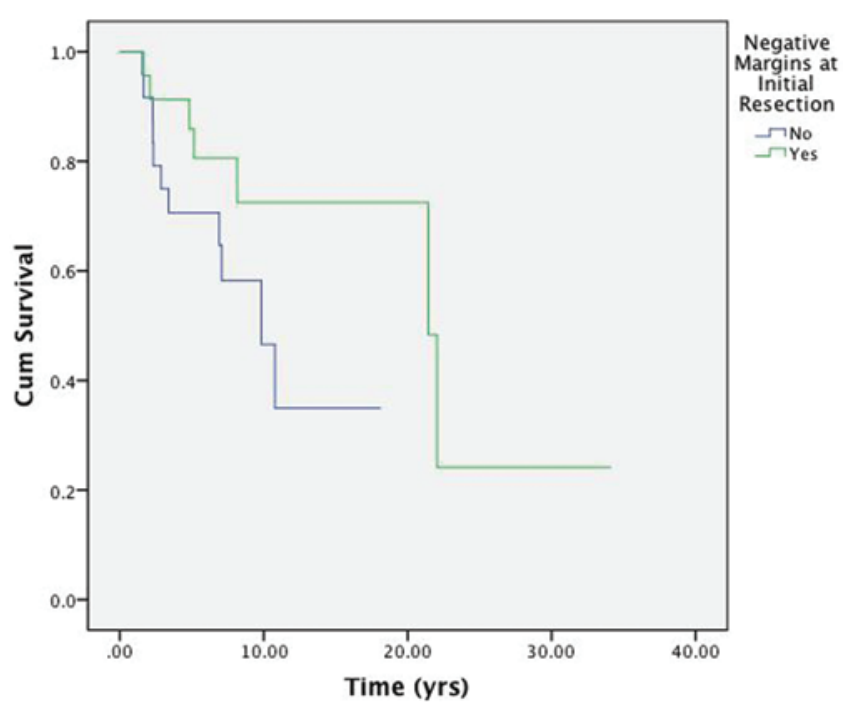

FIG. 1. Kaplan-Meier curve demonstrating improved OS for patients with negative margins $(p=0.035)$. Cum $=$ cumulative. Figure is available in color online only.

sion, perineural extension, and association with delayed metastases ${ }^{19,24,29,33}$ Histologically, these tumors are subclassified into 3 categories: tubular, cribriform, and solid. However, sharp demarcation among these categories is difficult because different regions of a single tumor may have a different preponderance of one category versus another. ${ }^{5,24,53,54}$ Molecularly, epidermal growth factor receptor (EGFR), c-kit, and vascular endothelial growth factor (VEGF) have been associated with ACC, although a recent study found no correlation between EGFR, c-kit, and VEGF with respect to prognosis or recurrence. ${ }^{34}$

Here we report the largest and longitudinally most complete series (8.2 years mean follow-up) to date regarding ACC of the skull base. We have described 3 patterns of skull-base presentation with respect to the orbit, the anterior cranial base, and the lateral cranial base, with the maxilla as the epicenter. Of note, the location of the tumor's epicenter was not associated with differing survival, implying that a maximal resection strategy is applied equally regardless of tumor location (Fig. 2). A focus on the skull base is important because ACC that traverses the skull base by erosive disease or perineural extension is known to negatively influence oncological outcomes.

Our 5- and 10-year OS rates were $78 \%$ and $50 \%$, respectively, with an average OS of the study population of $15.6 \pm 2.4$ years and an average PFS of $7.3 \pm 0.85$ years. This is significantly better than in previously published smaller series, where focus on the skull base was inconsistent (OS range 4-8 yrs). ${ }^{9,23,24,42,51,53}$ Moreover, the 5-year local control rate of $82 \%$ approaches the rates $(94 \%)$ seen in ACC not involving the skull base. ${ }^{39}$ Our results indicate that 2 factors may influence a potentially dramatic improvement in OS. These include resections with negative microscopic margins (including exploration and resection of involved cranial nerves ${ }^{13}$ ) and the use of adjuvant radiotherapy, which demonstrated statistical significance even in multivariate analysis. ${ }^{38}$ Adjuvant radiation also seemed to triple PFS. On the other hand, the use of primary radiation therapy without surgery resulted in significant surviv-

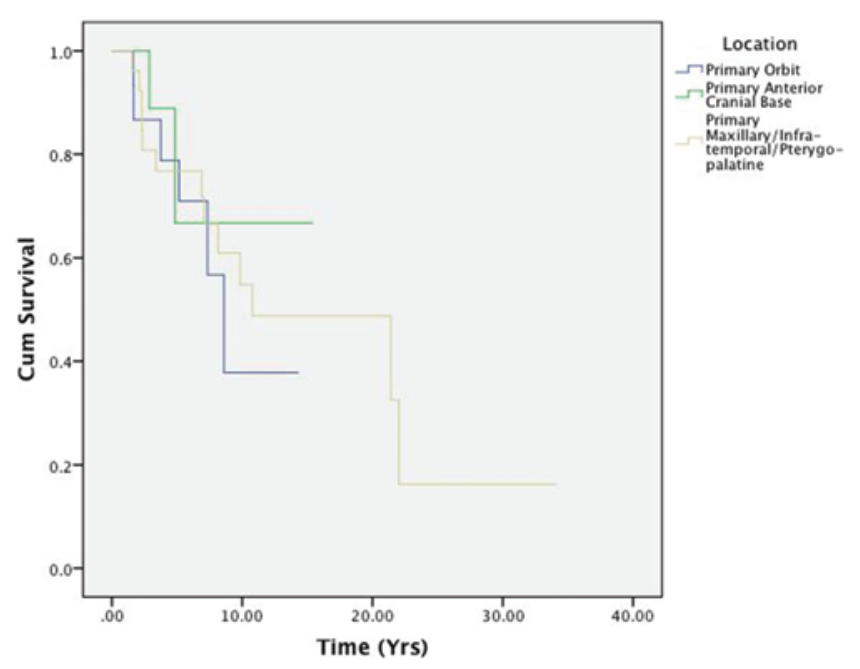

FIG. 2. Location of tumor epicenter did not alter the OS of study patients $(p=0.74)$. Figure is available in color online only.

al disadvantage. Of note, margin-negative resections did not significantly alter time to progression (Table 3). This probably reflects the variability in manner of progression (local vs distant metastasis). This comports with our data demonstrating mean time to progression and mean time to metastatic disease in relevant patients to be similar at 4.4 years. That said, the mean time to progression among those who progressed in our study was significantly improved

TABLE 3. Factors influencing time to progression in 51 patients with ACC*

\begin{tabular}{llc}
\hline \multicolumn{1}{c}{ Factor } & Time to Progression (yrs) & p Value \\
\hline Margins & & 0.99 \\
Negative & $7.3 \pm 1.2$ & \\
Positive & $7.4 \pm 1.2$ & \\
HR & 0.98 & \\
$95 \% \mathrm{Cl}$ & $0.5-1.99$ & 0.005 \\
\hline Adjuvant radiation at 1st op & & \\
Yes & $7.8 \pm 1.0$ & \\
No & $2.1 \pm 0.62$ & \\
HR & 4.4 & \\
$95 \% \mathrm{Cl}$ & $1.6-12.0$ & \\
\hline Adjuvant chemo at 1st op & & \\
Yes & $5.3 \pm 2.0$ & \\
No & $7.5 \pm 0.90$ & \\
HR & 1.4 & \\
$95 \% \mathrm{Cl}$ & $0.53-3.66$ & \\
\hline Cavernous sinus invasion & & \\
Yes & $6.4 \pm 1.1$ & \\
No & $8.0 \pm 1.2$ & \\
HR & 1.3 & \\
$95 \% \mathrm{Cl}$ & $0.69-2.6$ & \\
\hline Perineural invasion & & \\
Yes & $5.2 \pm 0.90$ & \\
No & $9.4 \pm 1.3$ & \\
HR & 0.46 & \\
$95 \% \mathrm{Cl}$ & $0.23-0.93$ & \\
\hline
\end{tabular}

\footnotetext{
* Data are presented as \pm SEM.
} 
compared with previous literature, where mean survivals were approximately an average of 2 years. ${ }^{25,27,39}$ Of note, repeat radiation given at time of recurrence and the use of chemotherapy were not associated with improved OS or time to progression in our series. Furthermore, stereotactic radiosurgery provided local control in $>70 \%$ of cases. In addition, we confirmed previous data showing that chemotherapy does not alter outcome in patients with ACC. ${ }^{38}$ Finally, the presence of perineural invasion was a significant, negative prognostic factor; its presence significantly impacted survival by $>50 \%$.

These improvements in oncological outcomes for patients with ACC involving skull base extension are a result of incremental progress over the last 4 decades. These improvements are attributable to more effective craniofacial resection strategies involving multidisciplinary teams, improved reconstruction options with vascularized flaps, recognition that piecemeal resections with negative margins afford oncological results similar to en bloc resections, and more effective adjuvant therapy including conformal radiation therapy. ${ }^{7,17,21,28,40}$ Endoscopic approaches have gained traction in recent years. Although further data are needed, it appears that oncological outcomes do not appreciably suffer after endoscopic resections as compared with traditional, open craniofacial resections as long as oncological principles are upheld. ${ }^{28}$ That said, this study describes patients who predominately received open craniofacial approaches given the advanced $\mathrm{T}$ stage of their disease (75\% of patients receiving endoscopic treatment required conversion to open surgeries). Another key advance in the treatment of ACC has been the recognition of perineural extension as a harbinger of poor outcome. $7,13,16,18,20,23,24,31$ As such, our strategy has been to maximally resect all perineural disease until negative margins are obtained or the risk of neurological complications (via carotid injury) precludes further resection..$^{13,46,47}$ Finally, the importance of bony resection cannot be underestimated, as ACC involving the lacrimal gland is best treated with orbitectomy rather than local resection. ${ }^{16}$ Our study confirmed the relative inefficacy of chemotherapy regimens in altering disease progression. It is worth noting that chemotherapy was generally deployed when bulky disease remained after surgery, or in circumstances of disease progression despite previous treatments of maximal cytoreductive surgery and conformal radiotherapy. Regardless, in no instance did chemotherapy halt disease progression. It should be noted, however, that chemotherapy can offer symptomatic relief without objective tumor response. .14,37 $^{-13}$

Our surgical strategy resulted in no mortality and minimal lasting morbidity across $>70$ procedures. Complications ranged from temporary postoperative respiratory failure, neck hematoma requiring evacuation, enopthalmos, to infection. There were no strokes or other vascular complications, reflecting our avoidance of aggressive manipulation or sacrifice of the ICA (18\% in another small skull-base study ${ }^{24}$ ). In fact, our average length of hospital stay was only $6.7 \pm 0.80$ days, which mostly reflects standard monitoring after free flap placement.

Our study limitations include its retrospective nature at a single institution. Moreover, the population reflects mostly patients with aggressive disease, although our re- sults should apply across the spectrum of ACC. Although this study represents the largest skull-base experience in the literature, the study population is still relatively small at 51 patients, preventing additional meaningful multivariate analysis. Additionally, quality-of-life measures were not performed in this study but are important in patients who undergo aggressive surgery, particularly for those procedures involving significant cosmetic deformity. ${ }^{35}$ It has been previously noted that the pathological subtypes of cribriform, solid, and tubular components can influence outcome. However, the vast majority of the patients in our series were mixed pathologically without a standardized methodology of quantifying the solid component of tumor, thus rendering statistical analysis unreliable. ${ }^{38} \mathrm{Fi}-$ nally, the availability of molecular status on these tumors was inconsistent, making inferences regarding molecular influence impossible.

\section{Conclusions}

Adenoid cystic carcinoma is an aggressive disease, with added complexity when involving the skull base. A strategy of maximal resection with adjuvant radiotherapy should be used to optimize survival. Chemotherapy does not appear to confer benefit.

\section{References}

1. Agulnik M, Cohen EW, Cohen RB, Chen EX, Vokes EE, Hotte SJ, et al: Phase II study of lapatinib in recurrent or metastatic epidermal growth factor receptor and/or erbB2 expressing adenoid cystic carcinoma and non adenoid cystic carcinoma malignant tumors of the salivary glands. J Clin Oncol 25:3978-3984, 2007

2. Airoldi M, Bumma C, Bertetto O, Riella AM, Gabriele P, Succo G, et al: Vinorelbine for recurrent adenocarcinomalike salivary gland malignancies. Eur J Cancer B Oral Oncol 32B: 213-214, 1996

3. Alvi A, Myers E, Carrau R: Malignant Tumors of the salivary glands, in Myers E, Suen J (eds): Cancer of the Head and Neck, ed 3. Philadelphia: W.B. Saunders, 1996, pp 525d561

4. Anderson JN Jr, Beenken SW, Crowe R, Soong SJ, Peters G, Maddox WA, et al: Prognostic factors in minor salivary gland cancer. Head Neck 17:480-486, 1995

5. Batsakis JG, Luna MA, el-Naggar A: Histopathologic grading of salivary gland neoplasms: III. Adenoid cystic carcinomas. Ann Otol Rhinol Laryngol 99:1007-1009, 1990

6. Bilsky MH, Bentz B, Vitaz T, Shah J, Kraus D: Craniofacial resection for cranial base malignancies involving the infratemporal fossa. Neurosurgery 57 (4 Suppl):339-347, 2005

7. Bristol IJ, Ahamad A, Garden AS, Morrison WH, Hanna EY, Papadimitrakopoulou VA, et al: Postoperative radiotherapy for maxillary sinus cancer: long-term outcomes and toxicities of treatment. Int J Radiat Oncol Biol Phys 68:719-730, 2007

8. Chen AM, Bucci MK, Weinberg V, Garcia J, Quivey JM, Schechter NR, et al: Adenoid cystic carcinoma of the head and neck treated by surgery with or without postoperative radiation therapy: prognostic features of recurrence. Int J Radiat Oncol Biol Phys 66:152-159, 2006

9. Conley J, Dingman DL: Adenoid cystic carcinoma in the head and neck (cylindroma). Arch Otolaryngol 100:81-90, 1974

10. Cox DR: Regression models and life tables. J R Stat Soc 34:187-220, 1972 
11. Creagan ET, Woods JE, Rubin J, Schaid DJ: Cisplatin-based chemotherapy for neoplasms arising from salivary glands and contiguous structures in the head and neck. Cancer 62:2313-2319, 1988

12. de Haan LD, De Mulder PH, Vermorken JB, Schornagel JH, Vermey A, Verweij J: Cisplatin-based chemotherapy in advanced adenoid cystic carcinoma of the head and neck. Head Neck 14:273-277, 1992

13. DeMonte F, Hanna E: Transmaxillary exploration of the intracranial portion of the maxillary nerve in malignant perineural disease. Technical note. J Neurosurg 107:672-677, 2007

14. Dodd RL, Slevin NJ: Salivary gland adenoid cystic carcinoma: a review of chemotherapy and molecular therapies. Oral Oncol 42:759-769, 2006

15. Dreyfuss AI, Clark JR, Fallon BG, Posner MR, Norris CM Jr, Miller D: Cyclophosphamide, doxorubicin, and cisplatin combination chemotherapy for advanced carcinomas of salivary gland origin. Cancer 60:2869-2872, 1987

16. Esmaeli B, Golio D, Kies M, DeMonte F: Surgical management of locally advanced adenoid cystic carcinoma of the lacrimal gland. Ophthal Plast Reconstr Surg 22:366-370, 2006

17. Feiz-Erfan I, Suki D, Hanna E, DeMonte F: Prognostic significance of transdural invasion of cranial base malignancies in patients undergoing craniofacial resection. Neurosurgery 61:1178-1185, 2007

18. Fordice J, Kershaw C, El-Naggar A, Goepfert H: Adenoid cystic carcinoma of the head and neck: predictors of morbidity and mortality. Arch Otolaryngol Head Neck Surg 125:149-152, 1999

19. Fortuna A, Gambacorta D: Cylindroma in the region of the gasserian ganglion. Case report. J Neurosurg 34:427-431, 1971

20. Gandour-Edwards R, Kapadia SB, Barnes L, Donald PJ, Janecka IP: Neural cell adhesion molecule in adenoid cystic carcinoma invading the skull base. Otolaryngol Head Neck Surg 117:453-458, 1997

21. Ganly I, Patel SG, Singh B, Kraus DH, Bridger PG, Cantu G, et al: Complications of craniofacial resection for malignant tumors of the skull base: report of an International Collaborative Study. Head Neck 27:445-451, 2005

22. Garden AS, Weber RS, Morrison WH, Ang KK, Peters LJ: The influence of positive margins and nerve invasion in adenoid cystic carcinoma of the head and neck treated with surgery and radiation. Int J Radiat Oncol Biol Phys 32:619-626, 1995

23. Gomez DR, Hoppe BS, Wolden SL, Zhung JE, Patel SG, Kraus DH, et al: Outcomes and prognostic variables in adenoid cystic carcinoma of the head and neck: a recent experience. Int J Radiat Oncol Biol Phys 70:1365-1372, 2008

24. Gormley WB, Sekhar LN, Wright DC, Olding M, Janecka IP, Snyderman $\mathrm{CH}$, et al: Management and long-term outcome of adenoid cystic carcinoma with intracranial extension: a neurosurgical perspective. Neurosurgery 38:1105-1113, 1996

25. Haddad A, Enepekides DJ, Manolidis S, Black M: Adenoid cystic carcinoma of the head and neck: a clinicopathologic study of 37 cases. J Otolaryngol 24:201-205, 1995

26. Haddad R, Posner MR: Palliative chemotherapy in patients with salivary gland neoplasms and preliminary reports of 2 recent phase II studies with trastuzumab and gemcitabine. Clin Adv Hematol Oncol 1:226-228, 2003

27. Haddad RI, Posner MR, Busse PM, Norris CM Jr, Goguen LA, Wirth LJ, et al: Chemoradiotherapy for adenoid cystic carcinoma: preliminary results of an organ sparing approach. Am J Clin Oncol 29:153-157, 2006

28. Hanna E, DeMonte F, Ibrahim S, Roberts D, Levine N, Kupferman M: Endoscopic resection of sinonasal cancers with and without craniotomy: oncologic results. Arch Otolaryngol Head Neck Surg 135:1219-1224, 2009
29. Hara H, Tanaka Y, Tsuji T, Momose G, Kobayashi S: Intracranial adenoid cystic carcinoma. A case report. Acta Neurochir (Wien) 69:291-295, 1983

30. Hentschel SJ, Vora Y, Suki D, Hanna EY, DeMonte F: Malignant tumors of the anterolateral skull base. Neurosurgery 66:102-112, 2010

31. Issing PR, Hemmanouil I, Stöver T, Kempf HG, Wilkens L, Heermann R, et al: Adenoid cystic carcinoma of the skull base. Skull Base Surg 9:271-275, 1999

32. Kaplan EL, Meier P: Nonparametric estimation from incomplete observations. J Am Stat Assoc 53:457-481, 1958

33. Koka VN, Tiwari RM, van der Waal I, Snow GB, Nauta J, Karim AB, et al: Adenoid cystic carcinoma of the salivary glands: clinicopathological survey of 51 patients. J Laryngol Otol 103:675-679, 1989

34. Lee SK, Kwon MS, Lee YS, Choi SH, Kim SY, Cho KJ, et al: Prognostic value of expression of molecular markers in adenoid cystic cancer of the salivary glands compared with lymph node metastasis: a retrospective study. World J Surg Oncol 10:266, 2012

35. Levine NB, Demonte F: Functional outcome in the neurosurgical patient and its impact on quality of life. Skull Base 20:19-22, 2010

36. Licitra L, Cavina R, Grandi C, Palma SD, Guzzo M, Demicheli R, et al: Cisplatin, doxorubicin and cyclophosphamide in advanced salivary gland carcinoma. A phase II trial of 22 patients. Ann Oncol 7:640-642, 1996

37. Locati LD, Bossi P, Perrone F, Potepan P, Crippa F, Mariani $\mathrm{L}$, et al: Cetuximab in recurrent and/or metastatic salivary gland carcinomas: A phase II study. Oral Oncol 45:574-578, 2009

38. Lupinetti AD, Roberts DB, Williams MD, Kupferman ME, Rosenthal DI, Demonte F, et al: Sinonasal adenoid cystic carcinoma: the M. D. Anderson Cancer Center experience. Cancer 110:2726-2731, 2007

39. Mendenhall WM, Morris CG, Amdur RJ, Werning JW, Hinerman RW, Villaret DB: Radiotherapy alone or combined with surgery for adenoid cystic carcinoma of the head and neck. Head Neck 26:154-162, 2004

40. Patel SG, Singh B, Polluri A, Bridger PG, Cantu G, Cheesman $\mathrm{AD}$, et al: Craniofacial surgery for malignant skull base tumors: report of an international collaborative study. Cancer 98:1179-1187, 2003

41. Posner MR, Ervin TJ, Weichselbaum RR, Fabian RL, Miller D: Chemotherapy of advanced salivary gland neoplasms. Cancer 50:2261-2264, 1982

42. Shotton JC, Schmid S, Fisch U: The infratemporal fossa approach for adenoid cystic carcinoma of the skull base and nasopharynx. Otolaryngol Clin North Am 24:1445-1464, 1991

43. Simpson JR, Thawley SE, Matsuba HM: Adenoid cystic salivary gland carcinoma: treatment with irradiation and surgery. Radiology 151:509-512, 1984

44. Skibba JL, Hurley JD, Ravelo HV: Complete response of a metastatic adenoid cystic carcinoma of the parotid gland to chemotherapy. Cancer 47:2543-2548, 1981

45. Spiro RH: Distant metastasis in adenoid cystic carcinoma of salivary origin. Am J Surg 174:495-498, 1997

46. St Clair EG, DeMonte F: Adenoid cystic carcinoma, Part I: Clinical and radiologic evaluation. Contemp Neurosurg 31(26): 1-5, 2009

47. St Clair EG, DeMonte F: Adenoid cystic carcinoma, Part II: Assessing surgical and nonsurgical treatments and management. Contemp Neurosurg 32(1):1-6, 2010

48. Tannock IF, Sutherland DJ: Chemotherapy for adenocystic carcinoma. Cancer 46:452-454, 1980

49. Venook AP, Tseng A Jr, Meyers FJ, Silverberg I, Boles R, Fu KK, et al: Cisplatin, doxorubicin, and 5-fluorouracil chemotherapy for salivary gland malignancies: a pilot study 
of the Northern California Oncology Group. J Clin Oncol 5:951-955, 1987

50. Vermorken JB, Verweij J, de Mulder PH, Cognetti F, Clavel M, Rodenhuis S, et al: Epirubicin in patients with advanced or recurrent adenoid cystic carcinoma of the head and neck: a phase II study of the EORTC Head and Neck Cancer Cooperative Group. Ann Oncol 4:785-788, 1993

51. Vincentelli F, Grisoli F, Leclercq TA, Ardaud B, DiazVasquez P, Hassoun J: Cylindromas of the base of the skull. Report of four cases. J Neurosurg 65:856-859, 1986

52. Williams MD, Al-Zubidi N, Debnam JM, Shinder R, DeMonte F, Esmaeli B: Bone invasion by adenoid cystic carcinoma of the lacrimal gland: preoperative imaging assessment and surgical considerations. Ophthal Plast Reconstr Surg 26:403-408, 2010

53. Witt RL: Adenoid cystic carcinoma of the minor salivary glands. Ear Nose Throat J 70:218-222, 1991
54. Yamamoto Y, Saka T, Makimoto K, Takahashi H: Histological changes during progression of adenoid cystic carcinoma. J Laryngol Otol 106:1016-1020, 1992

\section{Author Contributions}

Conception and design: DeMonte, Ramakrishna. Acquisition of data: DeMonte, Ramakrishna. Analysis and interpretation of data: DeMonte, Ramakrishna. Drafting the article: DeMonte, Ramakrishna. Critically revising the article: all authors. Reviewed submitted version of manuscript: DeMonte, Ramakrishna.

\section{Correspondence}

Franco DeMonte, MD Anderson Cancer Center, 1515 Holcombe Blvd., Ste. 442, Houston, TX 77030. email: fdemonte@ mdanderson.org. 